\title{
Decreased expression of GBA3 correlates with a poor prognosis in hepatocellular carcinoma patients
}

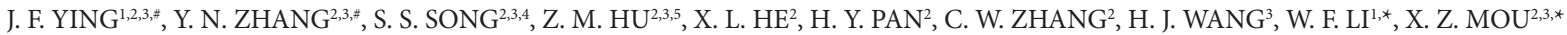

${ }^{1}$ Key Laboratory of Molecular Animal Nutrition of the Ministry of Education, Institute of Feed Science, College of Animal Sciences, Zhejiang University, Hangzhou, Zhejiang, China; ${ }^{2}$ Key Laboratory of Tumor Molecular Diagnosis and Individualized Medicine of Zhejiang Province, Zhejiang Provincial People's Hospital, Hangzhou, Zhejiang, China; ${ }^{3}$ Clinical Research Institute, Zhejiang Provincial People's Hospital, Hangzhou, Zhejiang, China; ${ }^{4}$ College of Life Science, Zhejiang Chinese Medical University, Hangzhou, Zhejiang, China; Department of Hepatobiliary and Pancreatic Surgery, Zhejiang Provincial People's Hospital, Hangzhou, Zhejiang, China

${ }^{*}$ Correspondence: mouxz@zju.edu.cn; wfli@zju.edu.cn

"Contributed equally to this work.

Received September 28, 2019 / Accepted December 8, 2019

\begin{abstract}
Beta-glucosidase (GBA), also known as acid $\beta$-glucosidase, exhibits an activity of glucosylceramidase (EC 3.2.1.45). Three main isoforms of $\beta$-glucosidases have been identified in mammals: GBA1, GBA2, and GBA3. The deficiency of these enzymes leads to glucosylceramide accumulation, resulting in Gaucher's disease. The present study is focused on the cytosolic $\beta$-glucosidase, GBA3, and its relationship with hepatocellular carcinoma (HCC). The expression of GBA3 mRNA in HCC was evaluated first using the TCGA database, and then by immunohistochemistry using tissue microarrays of 328 clinically characterized HCC samples and 151 non-tumor liver controls. Moreover, the presence of a correlation between GBA3 expression and clinicopathological characteristics of patients was examined. The obtained results indicated that the expression of GBA3 mRNA was significantly lower in HCC than in the adjacent non-tumor liver tissues. The expression of GBA3 was inversely related to the number of tumors $(p=0.041)$, tumor size $(p<0.001)$, Edmondson grade $(p=0.007)$, microvascular invasion $(\mathrm{p}=0.049)$, patient status $(\mathrm{p}<0.001)$, and $\alpha$-fetoprotein level $(\mathrm{p}<0.001)$. Patients exhibiting low GBA3 expression had a shorter survival time than those with high expression $(\mathrm{p}<0.001)$. In conclusion, the decreased GBA3 expression is strongly associated with a poor prognosis in HCC patients, and GBA3 may be a potential therapeutic target for HCC.
\end{abstract}

Key words: glucosidase, hepatocellular carcinoma, immunohistochemistry, bioinformatics

Hepatocellular carcinoma (HCC) is the sixth most prevalent neoplasm and the second leading cause of cancer-related deaths worldwide, with the high risk occurring in China and Eastern Africa. Moreover, the incidence continues to increase [1-3]. Approximately 750,000 new cases of liver cancer are reported per year globally, creating a medical emergency that must be solved. The development of medical technology yielded significant progress in HCC therapy, providing treatments such as liver transplant, surgical resection, embolization, stereotactic body radiation therapy, ablation, and chemotherapy. Despite these accomplishments, the five-year survival rate of HCC remains poor [4], partly due to the fact that these therapies are effective when HCC is detected at an early stage. Therefore, early diagnosis of HCC is essential for effective therapies and favorable prognosis, and the identification of biomarkers of HCC is an urgent necessity.
Cytosolic $\beta$-glucosidase (GBA3, EC 3.2.1.21), also known as the klotho-related protein, is present in the cytosol of cells and is implicated in human aging $[5,6]$. GBA3 is an enzyme with broad substrate specificity for the glycone moiety of various aryl-glycosides including $\beta$-D-fucosides, $\alpha$-L-arabi nosides, $\beta$-D-glucosides, $\beta$-D-galactosides, $\beta$-L-xylosides, and $\beta$-D-arabinosides. In addition, GBA3 displays a conspicuous hydrolytic activity for several common dietary xenobiotics [7-9]. The two other types of $\beta$-glucosidase expressed in humans are the lysosomal enzyme, $\beta$-glucosidase 1 (GBA1), and the non-lysosomal $\beta$-glucosidase 2 (GBA2) $[10,11]$. GBA1 and GBA2 exhibit optimal activity at acidic $\mathrm{pH}$ values [12], while GBA3 has the highest activity at neutral $\mathrm{pH}$ [13]. GBA3 is a $53 \mathrm{kDa}$ protein with a pI of $4.5-4.6$ and is predominantly expressed in the liver, kidney, intestine, and spleen of humans [14]. The lack of these enzymes is responsible for Gaucher's disease (GD), one of the hereditary lysosomal 
storage disorders $[15,16]$. GD is an autosomal recessively innate disorder of sphingolipid metabolism characterized biochemically by a lack of lysosomal $\beta$-glucosidase [17, 18], which leads to the accumulation of the hydrophobic glucocerebroside in reticuloendothelial cells, particularly in the spleen, bone marrow, and liver [18]. In several cases, the accumulation of glucocerebroside in cells throughout the body leads to progressive hepatosplenomegaly, anemia, thrombocytopenia, skeletal disease, and immune dysregulation. Additionally, GD is associated with a higher incidence of malignant cancer $[19,20]$. For example, 3 of the 239 patients with GD were diagnosed with multiple myeloma in a 1982 study of Lee [21]. Rosenbloom and collaborators had found that 10 of 2,742 GD patients had multiple myeloma diagnosed after the age of 50 years, and, except for hematological malignancies, solid tumors in several organs have been reported [20, 22-25]. Effective treatments for GD include enzyme replacement and substrate reduction [26, 27]. However, the latter has the potential to increase the risk of liver complications, such as fibrosis and cirrhosis [28-30]. Importantly, complications of GD include the development of HCC [31-34].

By utilizing the data from the UALCAN web resource, the present study documented that the expression of GBA3 was significantly reduced in HCC tissues. Subsequently, GBA3 expression was evaluated by immunohistochemistry in 328 HCC samples and 151 non-tumorous liver tissues. Finally, the relationship between GBA3 expression, clinicopathological parameters, and the overall patient survival rate was determined.

\section{Patients and methods}

UALCAN database analysis. A meta-analysis based on UALCAN database (http://ualcan.path.uab.edu/) was performed to compare the expression $g b a 3$ at the mRNA level between hepatocellular carcinoma and normal tissues, sample types, individual cancer stages or tumor grade were exhibited in particular.

Patients and tissue samples. All tissue samples were acquired by surgical resection at Zhejiang Provincial People's Hospital (Hangzhou, China) between January 2010 and December 2016. This study was approved by the Ethics Committee of Zhejiang Provincial People's Hospital. Written informed consent was provided by the patients. The whole tissue samples were fixed with $4 \%$ formalin for $24 \mathrm{~h}$ at room temperature embedded in paraffin and made into tissue microarrays (TMA), which were purchased from Shanghai Biochip Co., Ltd. (Shanghai, China). The TMAs included 328 tumor tissue samples and 151 adjacent non-tumorous liver tissue samples. The group of patients consisted of 266 males and 62 females with an average age of 56.95 years (range 25-90). Information regarding tumor size, number, location, Edmondson Grade, and tumor metastasis were collected from patient medical records. The survival time was defined as the time from the date of surgery to the date of mortality or the last day of follow up.

Immunohistochemical staining and evaluation. TMAs were then used for immunohistochemical staining. Briefly, baked at $70^{\circ} \mathrm{C}$ for 2 hours, deparaffinized and dehydrated using xylene and graded alcohol immediately. Subsequently, TMAs were boiled at $120^{\circ} \mathrm{C}$ using TE buffer in a high pressure cooker for $3 \mathrm{~min}$ to retrieve antigen. And then, TMAs were blocked with $3 \%(\mathrm{v} / \mathrm{v}) \mathrm{H}_{2} \mathrm{O}_{2}$ for 15 min to quench endogenous peroxidase activity followed by the incubation with $10 \%$ normal goat serum to reduce background non-specific binding at room temperature. After that the sections were incubated with a rabbit anti-human primary polyclonal antibody against GBA3 monoclonal antibody (Abcam, Cambridge, UK, EPR15892, 1:800 dilutions) at $4{ }^{\circ} \mathrm{C}$ overnight. Following 3 washes with PBS, biotin-labeled secondary antibody for $20 \mathrm{~min}$ at room temperature and incubated with streptavidin-biotinylated horseradish peroxidase-conjugated antibody for another $20 \mathrm{~min}$ at room temperature. Finally, the sections were stained with 3,3-diaminobenzidine (DAB) and counterstained with hematoxylin, dehydrated, washed, and mounted.

After immunohistochemical staining, the degree of GBA3 was independently scored by 2 pathologists without knowledge of the clinical data, based on the intensity and the proportion of positively stained cells. The staining intensity was scored as follows: $0=$ no staining; $1=$ weak staining; 2 $=$ medium staining and $3=$ strong staining. The proportion of stained cells were scored as follows: 0 for no cells stained; 1 for $1-25 \%$ cells stained; 2 for $26-50 \%$ cells stained; 3 for $51-75 \%$ cells stained, and 4 for $>75 \%$ cells stained and then, to evaluate completely, multiplied the intensity and percentage of positive cells. Scores $\leq 2$ was used to define tumors for low GBA3 expression and $>2$ for high GBA3 expression.

Statistical analysis. Statistical analysis was performed using the Statistical Package of Social Sciences (SPSS, version 13.0; SPSS Inc, Chicago, IL). $\chi^{2}$ test analyzed the association between GBA3 expression and clinicopathological parameters. The overall survival curve was performed using the Kaplan-Meier method and further analyzed using the log-rank test. A p-value $<0.05$ was considered to indicate a statistically significant difference.

\section{Results}

Analysis of GBA3 expression based on the UALCAN database. To evaluate the expression of $g b a 3$ at the mRNA level in HCC and normal tissues, the Cancer Genome Atlas (TCGA) database was used. This analysis demonstrated that the gba3 mRNA expression was statistically significantly lower in HCC samples than in normal tissues, regardless of sample type, cancer stages, and tumor grade $(p<0.001$ in all cases; Figure 1). In the assessment of sample types, the median of normal $(\mathrm{n}=50)$ was 57.029 and of the primary tumor $(\mathrm{n}=371)$ was 8.295 . In the assessment of tumor grade, 

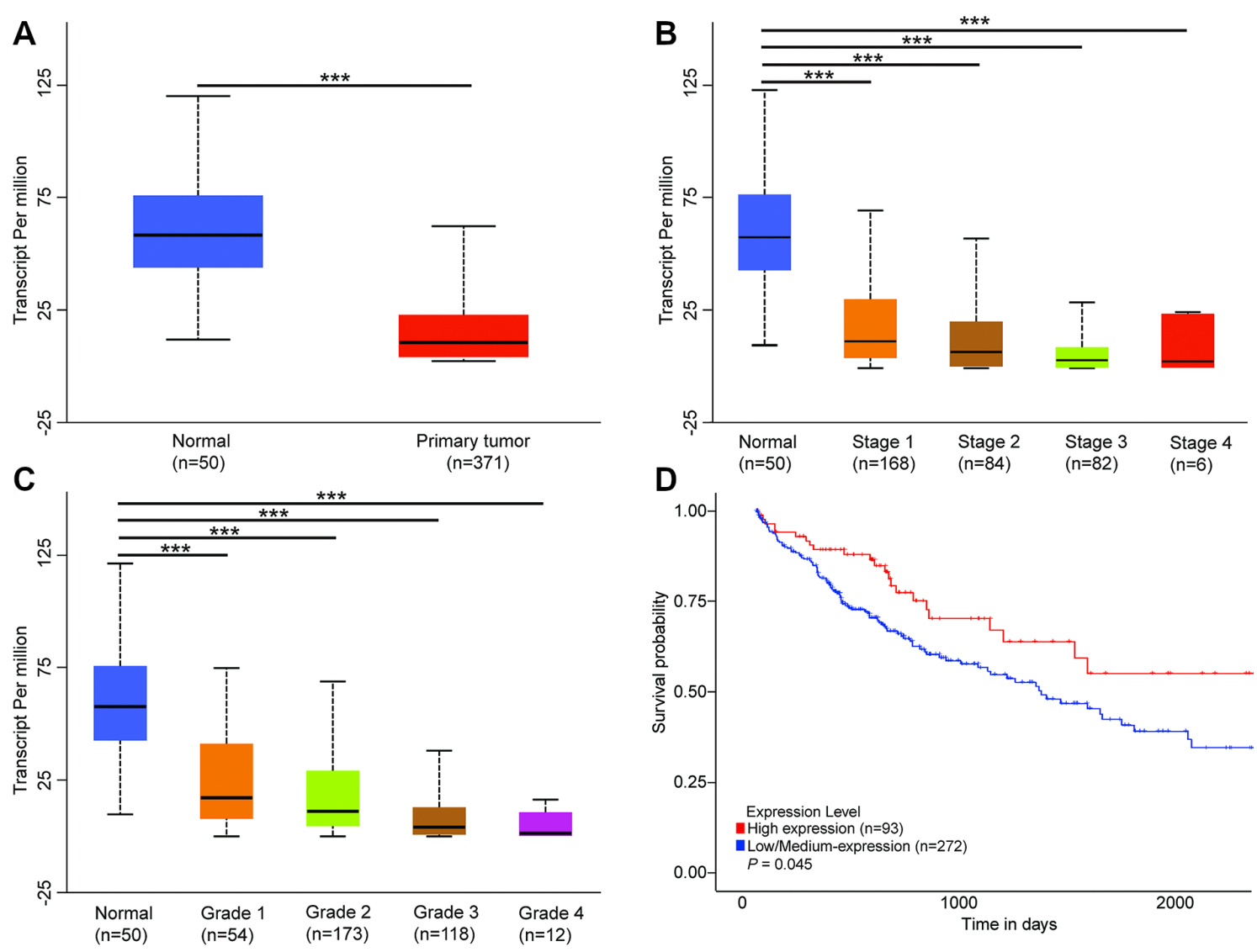

Figure 1. The mRNA expression of $g b a 3$ in HCC and normal tissues based on UALCAN database. A) The mRNA expression of $g b a 3$ in HCC and normal tissues based on sample types. mRNA expression of $g b a 3$ in normal and HCC based on individual B) cancer stage, C) tumor grade; D) HCC patients with low expression of GBA3 had decreased 5-year survival rate compared with those with high expression of this protein. Data are mean \pm SE. ${ }^{\star} \mathrm{p}<0.05$; ${ }^{* *} \mathrm{p}<0.01 ;{ }^{* * *} \mathrm{p}<0.001$

the median of grade $1(n=54)$ was 16.695 , of grade $2(n=173)$ was 10.694 , of grade $3(\mathrm{n}=118)$ was 3.984 , and of grade 4 $(\mathrm{n}=12)$ was 1.188. In individual cancer stages, the median of stage $1(n=168)$ was 11.553 , of stage $2(n=84)$ was 6.941 , of stage $3(n=82)$ was 3.573 , and of stage $4(n=6)$ was 2.193 .

Expression of GBA3 in HCC and non-tumorous tissues. The expression of GBA3 was further examined by immunohistochemical staining of HCC specimens and non-tumorous tissues, and it showed that the strong, moderate, and negative expression of GBA3 in HCC tissues, we also distinguished tumor tissues from different grades (Figures 2A-2D). By this approach, high expression of GBA3 was found in 129 of the $151(85.41 \%)$ cases of non-tumorous tissues, while this protein was significantly downregulated in HCC tissues; its expression was detected in 89 of 328 (27.81\%) HCC ( $p<0.001$; Table 1; Figure 2E).

Correlation between GBA3 protein expression and clinicopathologic parameters. The analysis of the correlation between the expression of GBA3 protein and clinical variables is presented in Table 2. We found that the expression of GBA3 in tumors was negatively correlated with the number of tumors $(\mathrm{p}=0.041)$, Edmondson grade $(\mathrm{p}=0.007)$, AFP $(\mathrm{p}<0.001)$, microvascular invasion $(\mathrm{p}=0.049)$, and patient status $(\mathrm{p}<0.001)$. There was no statistically significant correlation between GBA3 expression and other clinicopathological variables. In addition, we tested the relation of GBA3 expression and male's or/and female's age parameters in HCC. Unfortunately, the data was not significantly relative with the expression of GBA3 (Table 3).

Survival analysis. Kaplan-Meier analysis of 5-year survival indicated that this parameter was $80.6 \%$ in patients with high GBA3 expression, and $47.3 \%$ in patients with low GBA3 expression. The mean survival time of the patients with low GBA3 expression was $33.95 \pm 2.61$ months, which

Table 1. Expression of GBA3 in HCC and non-tumorous liver tissues.

\begin{tabular}{lcccc}
\hline \multirow{2}{*}{ Samples } & \multirow{2}{*}{ Number } & \multicolumn{2}{c}{ GBA3 expression } & \multirow{2}{*}{ p-value } \\
\cline { 3 - 4 } & & Negative & Positive & \\
\hline HCC & 328 & 239 & 89 & $<0.001$ \\
normal liver tissues & 151 & 22 & 129 & \\
\hline
\end{tabular}



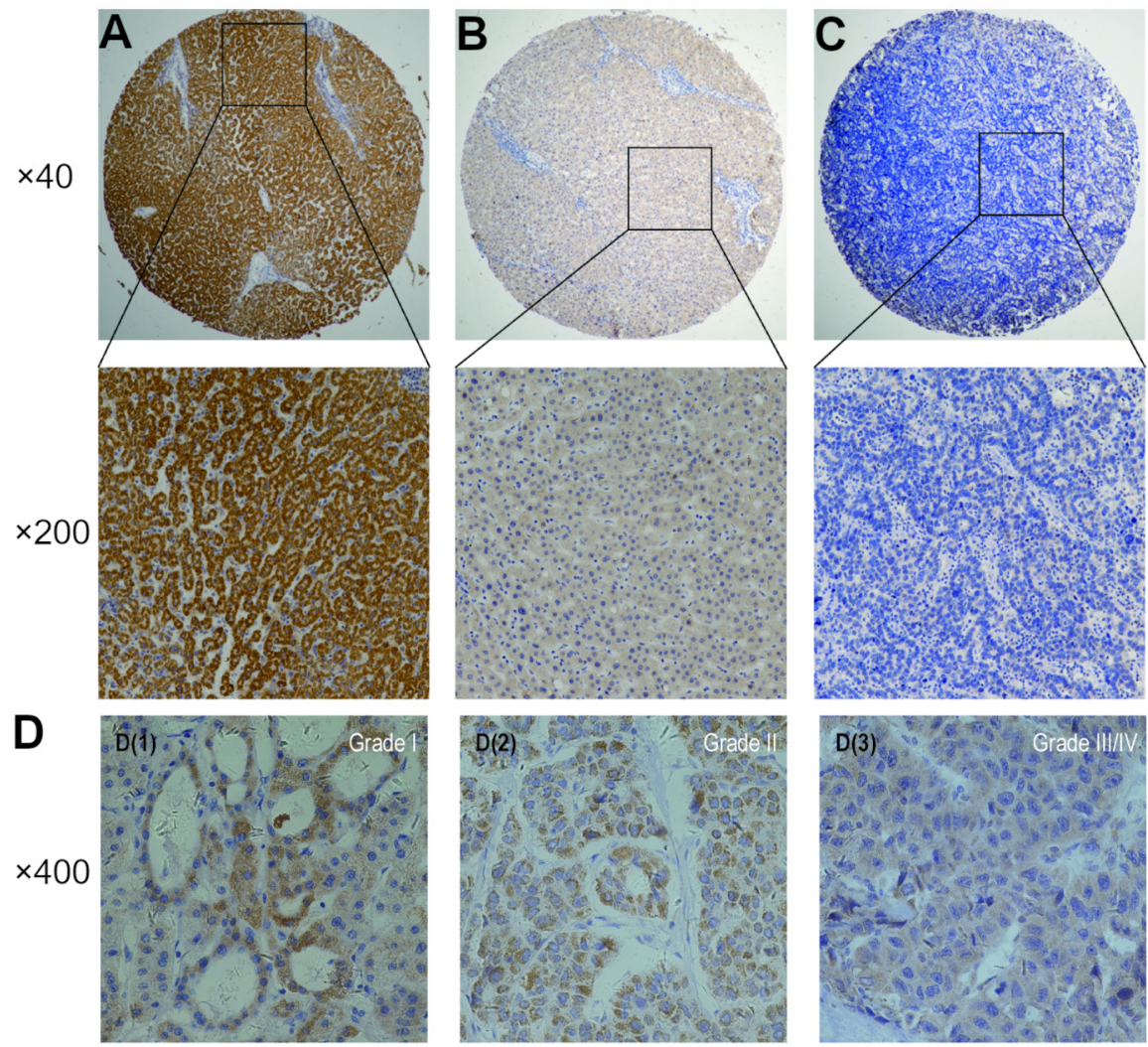

Figure 2. Immunohistochemical staining of GBA3 in tumorous and non-tumorous tissues. A) Strong expression. B) Moderate expression. C) Negative expression. D) The grade I, II, III, and IV in tumor tissues (the III and IV were grouped together due to the number limitation of cases). Magnification $\times 400, \times 200$, or $\times 40$, as indicated.

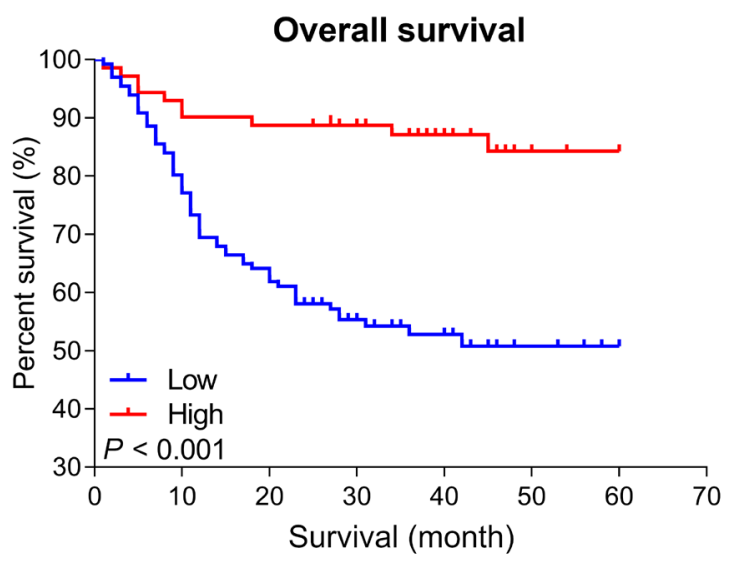

Figure 3. Kaplan-Meier survival curves of HCC patients with high or low GBA3 expression.

was obviously shorter than that of patients with high GBA3 expression (49.22 \pm 2.03 months, $\mathrm{p}<0.001$; log-rank test; Figure 3 ). Thus, low expression of GBA3 was significantly associated with poor overall survival.

\section{Discussion}

$\beta$-glucosidase (GBA) is capable of hydrolyzing glucosylceramide, and the cytosolic $\beta$-glucosidase (GBA3), a xenobiotic-metabolizing enzyme presents in liver and kidneys, hydrolyzes many types of glycosides $[8,9]$. The deficiency or mutation of GBA1, GBA2, and GBA3 results in an elevation of glucosylceramide level and then leads to GD, which is characterized by lysosomal storage disorders $[15,16]$. The GD has been reported linked to hepatosplenomegaly, anemia, thrombocytopenia, skeletal disease, immune dysregulation, and cancer [20,31]. Actually, the lack of GBA3 would induce lots of diseases, on the other hand, this enzyme replacement or substrate reduction represent effective treatment options for GD, but they are associated with an increased risk of liver complications $[28,29]$. Although it seems plausible that the deficiency or mutation of GBA3 could result in the complications of GD, few studies have been performed to address this issue, or to identify the potential association with HCC, one study discussed the link GBA3 to HCC at RNA level [35]. To further determine whether a direct relationship is presented between GBA3 and HCC, a comprehensive analysis was performed in this study. Through these researches, we could 
Table 2. Relationship between GBA3 expression and pathological parameters of HCC.

\begin{tabular}{|c|c|c|c|c|}
\hline \multirow{2}{*}{ Clinical parameters } & \multirow{2}{*}{ All case } & \multicolumn{2}{|c|}{ GBA3 } & \multirow{2}{*}{ p-value } \\
\hline & & Negative & Positive & \\
\hline Age (years) & & & & 0.942 \\
\hline$<55$ & 117 & 59 & 58 & \\
\hline$\geq 55$ & 194 & 97 & 97 & \\
\hline Gender & & & & 0.090 \\
\hline Male & 251 & 120 & 131 & \\
\hline Female & 60 & 36 & 24 & \\
\hline Size & & & & $<0.001$ \\
\hline$<5$ & 158 & 61 & 97 & \\
\hline$\geq 5$ & 145 & 90 & 55 & \\
\hline Tumor number & & & & 0.041 \\
\hline Single & 255 & 121 & 134 & \\
\hline Multiple & 56 & 35 & 21 & \\
\hline Edmondson Grade & & & & 0.007 \\
\hline $\mathrm{I}+\mathrm{II}$ & 194 & 84 & 110 & \\
\hline III & 111 & 66 & 45 & \\
\hline Metastasis & & & & 0.078 \\
\hline M0 & 278 & 136 & 142 & \\
\hline M1 & 27 & 18 & 9 & \\
\hline Microvascular invasion & & & & 0.049 \\
\hline Absence & 113 & 52 & 31 & \\
\hline Presence & 117 & 69 & 48 & \\
\hline Cirrhosis & & & & 0.968 \\
\hline Negative & 104 & 52 & 52 & \\
\hline Positive & 207 & 104 & 103 & \\
\hline AFP & & & & $<0.001$ \\
\hline$<50$ & 136 & 51 & 85 & \\
\hline$\geq 50$ & 119 & 73 & 46 & \\
\hline Status & & & & $<0.001$ \\
\hline Alive & 131 & 44 & 87 & \\
\hline Dead & 70 & 49 & 21 & \\
\hline HBV & & & & 0.710 \\
\hline Absence & 62 & 30 & 32 & \\
\hline Presence & 243 & 124 & 119 & \\
\hline
\end{tabular}

know the mechanism of complications about GD such as HCC better. The analysis performed in the present study documented differential expression of GBA3 in normal tissues and HCC and this finding may guide future research into the pathogenesis of HCC.

HCC is the sixth most prevailing neoplasm and the second leading cause of cancer-related deaths worldwide [1-3]. Although therapies targeting HCC have been developed, the five-year survival rate remains poor. To resolve this challenging situation, a greater effect is necessary in the medical field. HCC therapies are more effective in the early stage of cancer, thus timely diagnosis may benefit the treatment and prognosis. However, early detection of HCC presents a difficult clinical problem. Currently, an increased level of AFP is used as a marker in the early screening of
Table 3. Relationship between GBA3 expression and male's or female's age parameters of HCC.

\begin{tabular}{lcccc}
\hline \multirow{2}{*}{ Clinical parameters } & \multirow{2}{*}{ Number } & \multicolumn{2}{c}{ GBA3 expression } & \multirow{2}{*}{ p-value } \\
\cline { 3 - 4 } & & Negative & Positive & \\
\hline Male (age) & 252 & 120 & 132 & 0.559 \\
$<55$ years & 94 & 47 & 47 & \\
$\geq 55$ years & 158 & 73 & 85 & \\
Female (age) & 60 & 36 & 24 & 0.197 \\
$<55$ years & 24 & 12 & 12 & \\
$\geq 55$ years & 36 & 24 & 12 & \\
\hline
\end{tabular}

HCC, but only approximately $70 \%$ of HCC patients are AFP-positive [35]. Therefore, the identification of new and more specific biomarkers of HCC could improve the therapeutic outcomes and elucidate the underlying mechanisms of this disease. The current investigation was focused on the correlation of the expression of GBA3 with HCC progression, clinicopathological parameters, and the overall survival rate. Utilizing the UALCAN database, we have been the first to identify a lower expression of GBA3 HCC than in normal tissues. Conversely, as shown in this work, the expression of GBA3 is downregulated in HCC tissues. The expression was inversely correlated with the number of tumors $(\mathrm{p}=0.041)$, large tumor size $(\mathrm{p}<0.001)$, high Edmondson grade $(\mathrm{p}=0.007)$ (due to the small number of cases in grade 4 , we just listed it as grade 3$)$, increased microvascular invasion $(\mathrm{p}=0.049)$, high AFP levels $(\mathrm{p}<0.001)$. Moreover, patients with lower expression of GBA3 had shorter survival time than those with high expression of this protein $(\mathrm{p}<0.001)$. Interestingly, our study explored the expression of GBA3 at the protein level, which is in agreement with the result of Guan's research at the RNA level [35]. Since the obtained data point to a negative link between the expression of GBA3 and the level of AFP, the evaluation of GBA3 can serve, to some extent, as a better alternative to AFP measurement. The possibility can also be raised that the downregulation of GBA3 in HCC may promote tumor development and dissemination. We suggest that low expression of GBA3 occurs in many cases of HCC and warrants further clinical validation as a potential diagnostic and prognostic marker.

In conclusion, this study demonstrated the relevance of GBA3 in hepatocarcinogenesis and its potential as a marker of HCC. Online tools based on the generally accepted theories of bioinformatics were used to perform target gene analyses on tumor data from public databases and used the TMA for a clinical study. This approach can facilitate additional research into HCC genomics research and subsequent functional studies. Some deficiencies of the current study should be acknowledged. The online database has inherent limitations, such as the small number of stage 4 patients among the liver hepatocellular carcinoma samples, and the subjective character of the tissue microarray (TMA) analysis, meanwhile, in this research; we haven't gathered more cases of grade 4 yet and haven't searched the data about 
the stage in patients, which may affect the reliability of our results. However, these issues can be addressed in the future by performing more and more comprehensive studies.

Acknowledgements: This work was supported by the grants from the Zhejiang Province Bureau of Health (Nos. WKJ-ZJ-1812 to Z.M.H, 2018ZZ002 to Z.M.H, WKJ-ZJ-1710 to H.Y.P), National Science Foundation of China (Nos. 81602174 to H.J.W and 81672430 to X.Z.M), Funds of Science Technology Department of Zhejiang Province (Nos. LGF18H160024 to Z.M.H and LGF18H160025 to X.L.H), Zhejiang Provincial Natural Science Foundation of China (No. LY17H160062 to H.Y.P).

\section{References}

[1] BRAY F, FERLAY J, SOERJOMATARAM I, SIEGEL RL, TORRE LA et al. Global cancer statistics 2018: GLOBOCAN estimates of incidence and mortality worldwide for 36 cancers in 185 countries. CA Cancer J Clin 2018; 68: 394-424. https://doi.org/10.3322/caac.21492

[2] FORNER A, REIG M, BRUIX J. Hepatocellular carcinoma. Lancet 2018; 391: 1301-1314. https://doi.org/10.1016/ S0140-6736(18)30010-2

[3] JEMAL A, BRAY F, CENTER MM, FERLAY J, WARD E et al. Global cancer statistics. CA Cancer J Clin 2011; 61: 69-90. https://doi.org/10.3322/caac.20107

[4] MALUCCIO M, COVEY A. Recent progress in understanding, diagnosing, and treating hepatocellular carcinoma. CA Cancer J Clin 2012; 62: 394-399. https://doi.org/10.3322/ caac. 21161

[5] KURO-O M, MATSUMURA Y, AIZAWA H, KAWAGUCHI H, SUGA T et al. Mutation of the mouse klotho gene leads to a syndrome resembling ageing. Nature 1997; 390: 45-51. https://doi.org/10.1038/36285

[6] YAHATA K, MORI K, ARAI H, KOIDE S, OGAWA Y et al. Molecular cloning and expression of a novel klotho-related protein. J Mol Med (Berl) 2000; 78: 389-394. https://doi. org/10.1007/s001090000131

[7] BERRIN JG, CZJZEK M, KROON PA, MCLAUCHLAN WR, PUIGSERVER A et al. Substrate (aglycone) specificity of human cytosolic beta-glucosidase. Biochem J 2003; 373: 41-48. https://doi.org/10.1042/BJ20021876

[8] BERRIN JG, MCLAUCHLAN WR, NEEDS P, WILLIAMSON G, PUIGSERVER A et al. Functional expression of human liver cytosolic beta-glucosidase in Pichia pastoris. Insights into its role in the metabolism of dietary glucosides. Eur J Biochem 2002; 269: 249-258. https://doi.org/10.1046/ j.0014-2956.2001.02641.x

[9] DANIELS LB, COYLE PJ, CHIAO YB, GLEW RH, LABOW RS. Purification and characterization of a cytosolic broad specificity beta-glucosidase from human liver. J Biol Chem 1981; 256: 13004-13013.

[10] BOOT RG, VERHOEK M, DONKER-KOOPMAN W, STRIJLAND A, VAN MARLE J et al. Identification of the non-lysosomal glucosylceramidase as beta-glucosidase 2. J Biol Chem 2007; 282: 1305-1312. https://doi.org/10.1074/ jbc.M610544200
[11] SAITO M, ROSENBERG A. The fate of glucosylceramide (glucocerebroside) in genetically impaired (lysosomal betaglucosidase deficient) Gaucher disease diploid human fibroblasts. J Biol Chem 1985; 260: 2295-2300.

[12] MATERN H, HEINEMANN H, LEGLER G, MATERN S. Purification and characterization of a microsomal bile acid beta-glucosidase from human liver. J Biol Chem 1997; 272: 11261-11267. https://doi.org/10.1074/jbc.272.17.11261

[13] DEKKER N, VOORN-BROUWER T, VERHOEK $M$, WENNEKES T, NARAYAN RS et al. The cytosolic betaglucosidase GBA3 does not influence type 1 Gaucher disease manifestation. Blood Cells Mol Dis 2011; 46: 19-26. https:// doi.org/10.1016/j.bcmd.2010.07.009

[14] HAYS WS, JENISON SA, YAMADA T, PASTUSZYN A, GLEW RH. Primary structure of the cytosolic beta-glucosidase of guinea pig liver. Biochem J 1996; 319: 829-837. https://doi.org/10.1042/bj3190829

[15] MANWARING LP, JAMERSON PA, SLAUGH R. Lysosomal storage diseases. RN 2008; 71: 33-37; quiz 38.

[16] YILDIZ Y, HOFFMANN P, VOM DAHL S, BREIDEN B, SANDHOFF R et al. Functional and genetic characterization of the non-lysosomal glucosylceramidase 2 as a modifier for Gaucher disease. Orphanet J Rare Dis 2013; 8: 151. https:// doi.org/10.1186/1750-1172-8-151

[17] BRADY RO, KANFER JN, BRADLEY RM, SHAPIRO D. Demonstration of a deficiency of glucocerebroside-cleaving enzyme in Gaucher's disease. J Clin Invest 1966; 45: 1112 1115. https://doi.org/10.1172/JCI105417

[18] RAGHAVAN SS, TOPOL J, KOLODNY EH. Kolodny, Leukocyte beta-glucosidase in homozygotes and heterozygotes for Gaucher disease. Am J Hum Genet 1980; 32: 158-173.

[19] ELSTEIN D, ITZCHAKI M, MANKIN HJ. Skeletal involvement in Gaucher's disease. Baillieres Clin Haematol 1997; 10: 793-816. https://doi.org/10.1016/s0950-3536(97)80041-8

[20] ROSENBLOOM BE, WEINREB NJ, ZIMRAN A, KACENA KA, CHARROW J et al. Gaucher disease and cancer incidence: a study from the Gaucher Registry. Blood 2005; 105: 4569-4572. https://doi.org/10.1182/blood-2004-12-4672

[21] LEE RE. The pathology of Gaucher disease. Prog Clin Biol Res 1982; 95: 177-217.

[22] SHIRAN A, BRENNER B, LAOR A, TATARSKY I. Increased risk of cancer in patients with Gaucher disease. Cancer. 1993; 72(1): 219-24. https://doi.org/10.1002/10970142(19930701)72:1<219::aid-cncr2820720139>3.0.co;2-y

[23] ZIMRAN A, LIPHSHITZ I, BARCHANA M, ABRAHAMOV A, ELSTEIN D. Incidence of malignancies among patients with type I Gaucher disease from a single referral clinic. Blood Cells Mol Dis 2005; 34: 197-200. https://doi. org/10.1016/j.bcmd.2005.03.004

[24] ARENDS M, VAN DUSSEN L, BIEGSTRAATEN M, HOLLAK CE. Malignancies and monoclonal gammopathy in Gaucher disease; a systematic review of the literature. $\mathrm{Br}$ J Haematol 2013; 161: 832-842. https://doi.org/10.1111/ bjh.12335

[25] DE FOST M, VOM DAHL S, WEVERLING GJ, BRILL N, BRETT $S$ et al. Increased incidence of cancer in adult Gaucher disease in Western Europe. Blood Cells Mol Dis 2006; 36: 53-58. https://doi.org/10.1016/j.bcmd.2005.08.004 
[26] BARTON NW, BRADY RO, DAMBROSIA JM, DI BISCEGLIE AM, DOPPELT SH et al. Replacement therapy for inherited enzyme deficiency--macrophage-targeted glucocerebrosidase for Gaucher's disease. N Engl J Med 1991; 324: 1464-1470. https://doi.org/10.1056/NEJM199105233242104

[27] COX TM, DRELICHMAN G, CRAVO R, BALWANI M, BURROW TA et al. Eliglustat compared with imiglucerase in patients with Gaucher's disease type 1 stabilised on enzyme replacement therapy: a phase 3 , randomised, openlabel, non-inferiority trial. Lancet 2015; 385: 2355-2362. https://doi.org/10.1016/S0140-6736(14)61841-9

[28] FLESHNER PR, AUFSES AH JR, GRABOWSKI GA, ELIAS R. A 27-year experience with splenectomy for Gaucher's disease. Am J Surg 1991; 161: 69-75. https://doi. org/10.1016/0002-9610(91)90363-i

[29] LACHMANN RH, WIGHT DG, LOMAS DJ, FISHER NC, SCHOFIELD JP et al. Massive hepatic fibrosis in Gaucher's disease: clinico-pathological and radiological features. QJM 2000; 93: 237-244. https://doi.org/10.1093/qjmed/93.4.237

[30] BOHTE AE, VAN DUSSEN L, AKKERMAN EM, NEDERVEEN AJ, SINKUS $\mathrm{R}$ et al. Liver fibrosis in type I Gaucher disease: magnetic resonance imaging, transient elastography and parameters of iron storage. PLoS One 2013; 8: e57507. https://doi.org/10.1371/journal.pone.0057507
[31] ERJAVEC Z, HOLLAK CE, DE VRIES EG. Hepatocellular carcinoma in a patient with Gaucher disease on enzyme supplementation therapy. Ann Oncol 1999; 10: 243. https://doi. org/10.1023/a:1008306414822

[32] BREIDEN-LANGEN CM, BUCHSEL R, BRAMBS HJ, OEHLERT M, MATERN S. Coincidence of Gaucher disease with primary hepatocellular carcinoma. Leber Magen Darm 1991; 21: 126, 129-130.

[33] XU R, MISTRY P, MCKENNA G, EMRE S, SCHIANO T et al. Hepatocellular carcinoma in type 1 Gaucher disease: a case report with review of the literature. Semin Liver Dis 2005; 25: 226-229. https://doi.org/10.1055/s-2005-871201

[34] REGENBOOG M, VAN DUSSEN L, VERHEIJ J, WEINREB NJ, SANTOSA D et al. Hepatocellular carcinoma in Gaucher disease: an international case series. J Inherit Metab Dis 2018; 41: 819-827. https://doi.org/10.1007/s10545-0180142-y

[35] GUAN L, LUO Q, LIANG N, LIU H. A prognostic prediction system for hepatocellular carcinoma based on gene coexpression network. Exp Ther Med 2019; 17: 4506-4516. https://doi.org/10.3892/etm.2019.7494 